
Military Technical College Kobry El-Kobbah, Cairo, Egypt.

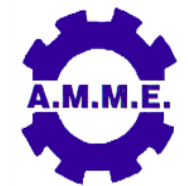

$18^{\text {th }}$ International Conference on Applied Mechanics and Mechanical Engineering.

\title{
SYNTHESIS OF Mg-Cu-Y BULK METALLIC GLASS PLATE VIA SPRAY FORMING PROCESS
}

\author{
R. H. Arison Kung ${ }^{1}$, M.-L. Ted Guo ${ }^{1}$, K. F. Chang ${ }^{1}$, Chi-Y. A. Tsao ${ }^{1, *}$, J.C. Huang ${ }^{2}$, \\ J.S.C. Jang ${ }^{3}$
}

\begin{abstract}
Mg-based amorphous alloys exhibit maximum specific strength among bulk metallic glass systems. In this study, a bulk $\mathrm{Mg}_{65} \mathrm{Cu}_{25} \mathrm{Y}_{10}$ deposit was produced successfully via spray forming process with higher cooling rate than conventional mold casting route. The deposit is $300 \mathrm{~mm}$ in diameter, $10 \mathrm{~mm}$ in thickness and $650 \mathrm{~g}$ in weight. The average porosity is about $10 \%$. The XRD and DSC results of the deposit look similar to that obtained from corresponding amorphous melt-spun ribbon. However, the measured composition of deposit varies slightly with the distance from substrate, which attribute to gravity effect of relative heavy element, like $Y$ and $\mathrm{Cu}$. The hardness of the deposit is higher than that of melt spun ribbons. The supercooled liquid region of the deposit determined from TMA technique is about 20K smaller than that obtained from DSC trace due to the stress induced nanocrystallzation occurred in the former. In addition, the volume reduction of deposit during TMA test was also smaller than that of ribbon and shows better dimension stability.
\end{abstract}

\section{KEY WORDS}

Bulk metallic glass, glass forming ability, spray forming, MgCuY

1 Department of Materials Science and Engineering, National Cheng Kung University, Tainan, Taiwan, ROC

2 Department of Materials Science and Engineering, National Sun Yat-Sen University, Kaohsiung, Taiwan, ROC

3 Department of Materials Science and Engineering, I-Shou University, Kaohsiung, Taiwan, ROC

Corresponding author, Email: tsao_cya@mail.ncku.edu.tw 


\section{INTRODUCTION}

A minute amorphous Au-Si alloy was first synthesized through extremely rapid solidification technique (over $10^{6} \mathrm{~K} / \mathrm{s}$ ) since 1960 [1]. Over the years, bulk amorphous alloys (BMG) with a magnified dimension have been intensively studied and became a promising candidate for mechanical applications. The advances of BMG are mainly due to the finding of new glass-forming composition with a critical cooling rate less than $102 \mathrm{~K} / \mathrm{s}$. Among these BMGs, Mg-based alloys possess maximum specific strength and suitable for fabricating light component parts.

The best glass former in $\mathrm{Mg}-\mathrm{Cu}-\mathrm{Y}$ system developed by Inoue group is Mg65Cu25Y10 alloy and the maximum specimen has ever been achieved was $4 \mathrm{~mm}$ in diameter via copper mold casting [2] and up to $7 \mathrm{~mm}$ in diameter via high pressure die casting [3]. However, Mg-Cu-Y BMGs also face two stringent challenges. Initially, they tend to catastrophically fail without much macroscopic plasticity during deformation. Some researchers have tried to add ceramics particles (e.g. TiB2) as obstacles against shear band propagation and the resultant composite have ductility up to $2 \%$ [1]. Next, the dimensional breakthrough of BMGs is less attainable through conventional liquid state processing, e.g. melt-spinning, drop-casting, and high pressure die casting [5] or solid state processing, e.g. mechanical alloying.

Spray-forming (Fig. 1) [6-7] is a novel process feasible for fabricating BMGs. It has adequate cooling rate $\left(10^{2} \sim 10^{3} \mathrm{~K} / \mathrm{sec}\right)$ equal or slightly larger than that of high pressure die casting, while offering a unlimited dimension growth through controlled supercooled liquid layer at the surface. In this study, an $\mathrm{Mg}_{65} \mathrm{Cu}_{25} \mathrm{Y}_{10} \mathrm{BMG}$ plate with $10 \mathrm{~mm}$ in maximum thickness was successfully done via this technique.

\section{EXPERIMENTAL}

Raw materials used in this study are all $99.9 \%$ in purity. $\mathrm{Cu}-\mathrm{Y}$ ingots were prepared by arc melting under Ti-getting argon atmosphere. The homogeneity of ingot was attained through remelting three times. Based on nominal composition, the ingot and Mg chips were remelted by induction melting under nitrogen gas. As spray forming began, molten metal was atomized with high pressure $\mathrm{N}_{2}$ into droplets and then collected onto a liquid nitrogen forced-cooled copper substrate to form a deposit of $300 \mathrm{~mm}$ in diameter, $10 \mathrm{~mm}$ in maximum thickness, and $650 \mathrm{~g}$ in weight, as seen in 0 . For comparison, Mg65Cu25Y10 amorphous ribbons with equal composition were also produced by melt-spinning process.

Chemical compositions of the deposit and ribbons were measured by inductively coupled plasma mass spectrometry (ICP) method. X-ray (Cu Ka) diffraction patterns were obtained from angles of $20-80^{\circ}$ at a scanning speed of $4 \% \mathrm{~min}$. The thermal analysis experiments were performed on a differential scanning calorimetry (DSC) at heating rate of $40 \mathrm{~K} / \mathrm{min}$.

Microstructural evolution of spray-formed specimen was also examined through back-scattered electron imaging (BEI) and quantitative wavelength diffraction spectrum (WDS) with a electron probe micro-analyzer (EPMA; JEOL-JXA-8900R). The micro Vickers hardness tests were conducted at load of $300 \mathrm{~g}$ and dwell time of $10 \mathrm{sec}$. The thermal stability evaluation was carried out with a thermo-mechanical 
analyzer (Perkin Elmer Diamond TMA) under 50 mN load.

\section{RESULTS AND DISCUSSION}

Figure 3 shows X-ray diffraction patterns obtained from various portions of sprayformed deposit, as well as that from as-melt-spun ribbon for comparison. The characteristic amorphous-like broad peaks are shown at angles of $20-40^{\circ}$ for all spray-formed and melt-spun specimens. The identical XRD results obtained from three portions $(1 \mathrm{~mm}, 5 \mathrm{~mm}, 9 \mathrm{~mm}$ from free surface) also demonstrate that the deposit is completely amorphous.

Figure 4 presents DSC traces for spray-formed plate and melt-spun ribbon at heating rate of $40 \mathrm{~K} / \mathrm{min}$, in which glass transition temperature $(\mathrm{Tg})$, which was determined by the intersection of two tangents at the start of the corresponding endotherm, and crystallization temperature (Tx) are also marked. Table 1 summarizes the results of DSC. The calculated reduced glass transition temperature (Trg) is almost identical to that measured by the Inoue group [8] for $\mathrm{Mg}_{65} \mathrm{Cu}_{25} \mathrm{Y}_{10}$. Based on XRD and DSC, the glass forming ability (GFA) of spray-forming specimen is comparable to that of meltspun. Meanwhile, spray forming can also magnify the dimension of BMG over that obtained in die casting due to more rapid heat dissipation rate in the former.

Microstructural evolution along cross-section direction for spray-formed plate is displayed in Fig. 5. The porosity for the near surface $(1-4 \mathrm{~mm}$ from free surface), the middle (4-7 $\mathrm{mm}$ from free surface) and the bottom (7-9 $\mathrm{mm}$ from free surface) of spray-formed plate is about $19.6 \%, 6.2 \%, 6.0 \%$, respectively. The formation of porosity is due to insufficient fill of melt during spray forming process. And, the finding of decreasing porosity as approaching substrate accounts for the increasing supercooled liquid (tend to fill pores) offered by forced-quenched effect.

Figure 6 to Fig. 9 show that ring patterns and non-crystalline images of spray formed plate at different sections are similar to that of the melt spun ribbon, which is of amorphous phase.

The cross-sectional chemical composition distribution for the plate measured by WDS method is shown in Fig. 10. The atomic percentage of $\mathrm{Cu}$ and $\mathrm{Y}$ increases as increasing distance from surface of deposit. Since the difference in atomic weight of $\mathrm{Mg}$ and $\mathrm{Cu} / \mathrm{Y}$, the gravity induced segregation of $\mathrm{Cu} / \mathrm{Y}$ become significant near substrate.

In Fig. 11, spray-formed plate has average hardness of $314 \mathrm{Hv}$ is higher than meltspun ribbon of $220 \mathrm{Hv}$.

Figure 12 shows the indentation of spray formed plate and melt spun ribbons. It could be obtained shear bands from the surface in (d) but not happen in (a) (c) due to different values of hardness.

In Fig. 13, the supercooled region $\Delta T\left(T_{x}-T_{g}\right)$ determined by TMA trace was about $50 \mathrm{~K}$ which was $20 \mathrm{~K}$ less than that determined by DSC trace. The reduced temperature interval is attributed to the nanocrystallization induced by applying compressive stress of $50 \mathrm{mN}$ during TMA [9-10]. 
In general, an amorphous specimen produced at higher quenching rate yield a larger volume reduction on heating. Volume reduction on heating is mainly due to structure relaxation. The volume reduction of spray-formed specimen is about $30 \%$ in magnitude of that of melt-spun ribbon, indicating its corresponding cooling rate also much less in magnitude.

\section{CONCLUSIONS}

1. An $\mathrm{Mg}_{65} \mathrm{Cu}_{25} \mathrm{Y}_{10}$ bulk metallic glass plate having $300 \mathrm{~mm}$ in diameter, $10 \mathrm{~mm}$ thickness and $650 \mathrm{~g}$ weight was successfully synthesized via spray forming process with a forced LN-cooled substrate.

2. The plate was characterized by XRD, DSC and TEM to be completely amorphous and comparable to the melt-spun ribbons.

3. The spray-formed plate exhibits porosities of $6 \%$ near substrate, $6.2 \%$ in the middle, and $19.6 \%$ near free surface, which is, however, expected to be eliminated during subsequent secondary processing into final products.

4. The composition of solvent element $\mathrm{Mg}$ gradually decreased from the top to bottom, and heavy solute elements, $\mathrm{Cu}$ and $\mathrm{Y}$, increase simultaneously due to gravity-induced segregation during melting practice.

5. The hardness of spray formed plate is higher than that of melt spun ribbons due to different cooling rate.

6. The supercooled liquid region of the deposit determined from TMA technique is about 20K smaller than that obtained from DSC trace due to the stress induced nano- crystallization occurred in the former.

7. During TMA test, the volume reduction of spray-formed deposit was also smaller than that of melt-spun ribbon and shows better dimension stability.

\section{REFERENCES}

[1] Klement, W., Willens, R. H. and Duwez, P.,Naure,1960,187,869.

[2] S.G. Kim, A Inoue, T. Masumoto, Mater. Trans. JIM 31(1990)929.

[3] A. Inoue. Kato, T. Zhang, S.G. Kim, T. Masumoto, Mater. Trans. JIM 32(1991)609.

[4] Y. K. Xu, H. Ma, J. Xu and E. Ma, Acta Materialia Vol. 53,no.6,1857 (2005).

[5] Inoue, T. Nakamura, N. Nishiyama and T. Masumoto, Mater. Transac., JIM, Vol. 33, No. 10, p937(1992)

[6] Guo, M.-L. T., Chi Y.A. Tsao, J. C. Huang, and J. S. C. Jang. Mater. Sci. Eng., 404 (1-2), 49-56.(2005)

[7] Guo, M.L. Ted, Chi Y.A. Tsao, J. C. Huang, and J. S.C. Jang., Intermetallics 14 (8-9),2006, 1069-1074.

[8] A. Inoue, Acta Mater. 48(2000), p279-306.

[9] H. M. Kimrua, A. Inoue, N. Nishiyama, K. Sasamori, O. Haruyama and T. Masumoto, Sci. Rep.,(1997), A43, 101.

[10] J. H. Mooij, Phys. Status Solidi, (1973)A17, 521 
Table 1. Thermal properties of as-spray-formed deposit and as-melt-spun ribbons obtained from DSC at heating rate of $40 \mathrm{~K} / \mathrm{min}(0.67 \mathrm{~K} / \mathrm{sec})$

\begin{tabular}{|c|c|c|c|c|c|c|}
\hline$(\mathrm{K})$ & $\mathrm{T}_{\mathrm{g}}$ & $T_{x}$ & $\Delta \mathrm{T}_{\mathrm{x}}$ & $\mathrm{T}_{1}$ & $\mathrm{~T}_{\mathrm{rg}}$ & Y \\
\hline As-melt spun ribbons & 428 & 489 & 61 & 760 & 0.563 & 0.412 \\
\hline $\begin{array}{l}\text { As-spray formed deposit } \\
\text { (1mm from surface) }\end{array}$ & 415 & 486 & 71 & 759 & 0.547 & 0.414 \\
\hline $\begin{array}{l}\text { As-spray formed deposit } \\
\text { (5 mm from surface) }\end{array}$ & 421 & 491 & 70 & 764 & 0.551 & 0.414 \\
\hline $\begin{array}{l}\text { As-spray formed deposit } \\
\text { (9 mm from surface) }\end{array}$ & 424 & 493 & 69 & 760 & 0.557 & 0.416 \\
\hline $\mathrm{Mg}_{65} \mathrm{Cu}_{25} \mathrm{Y}_{10}[5]$ & 425 & 486 & 61 & 771 & 0.551 & 0.406 \\
\hline
\end{tabular}

$$
\Delta T_{x}=T_{x}-T_{g} ; T_{r g}=T_{g} / T_{l} ; Y=T_{x} /\left(T_{g}+T_{l}\right)
$$

( $T_{g}$ : glass transition temperature, $T_{x}$ : crystallization temperature, $T_{i}$ : melting temperature; $T_{r g}$ : reduced glass transition temperature)

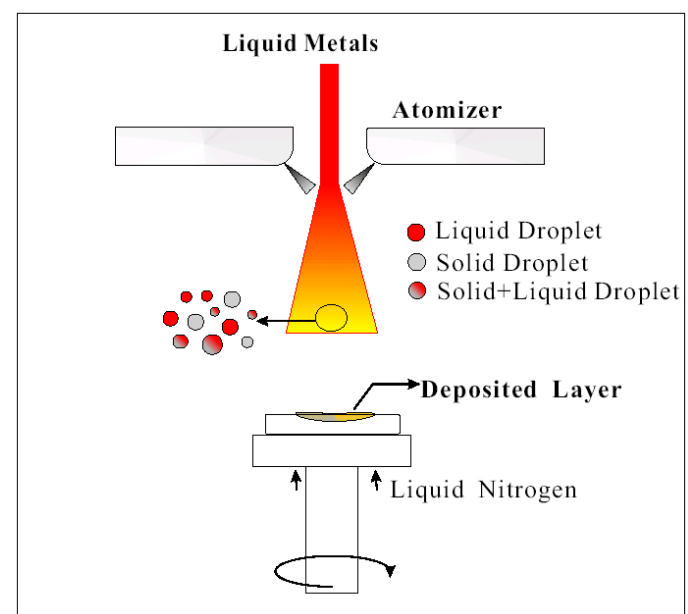

Fig. 1. Schematic diagram of spray-forming process.

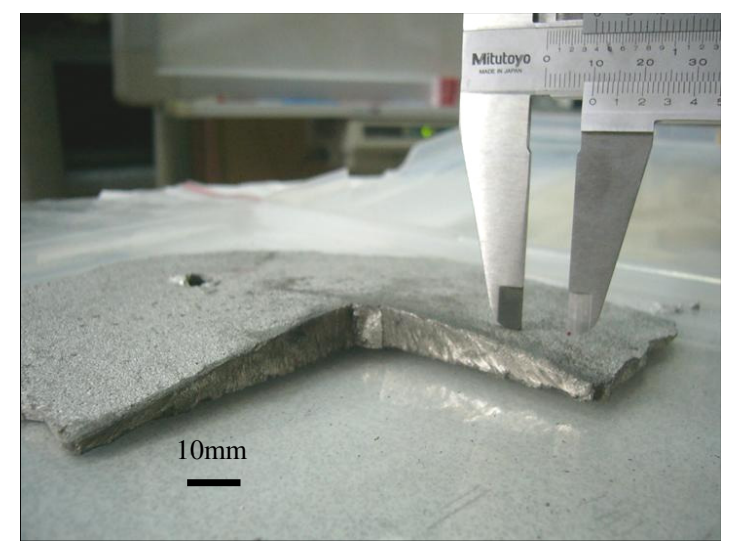

Fig. 2. The as-spray formed deposit of bulk metallic glass. 


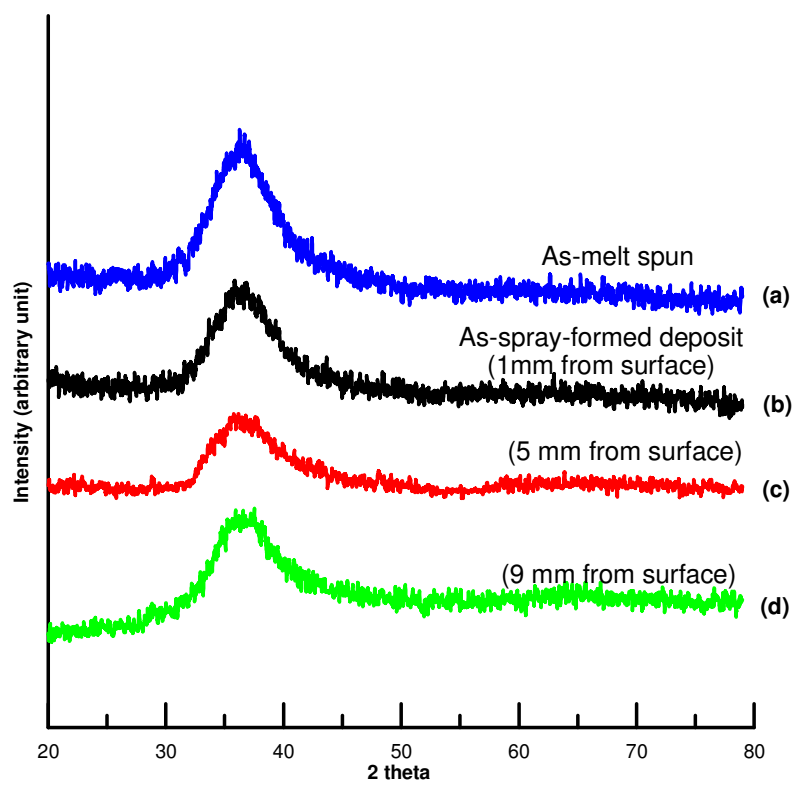

Fig. 3. XRD patterns of the as-melt spun ribbons in (a) and as-spray formed deposit with various locations from (b) to (d).

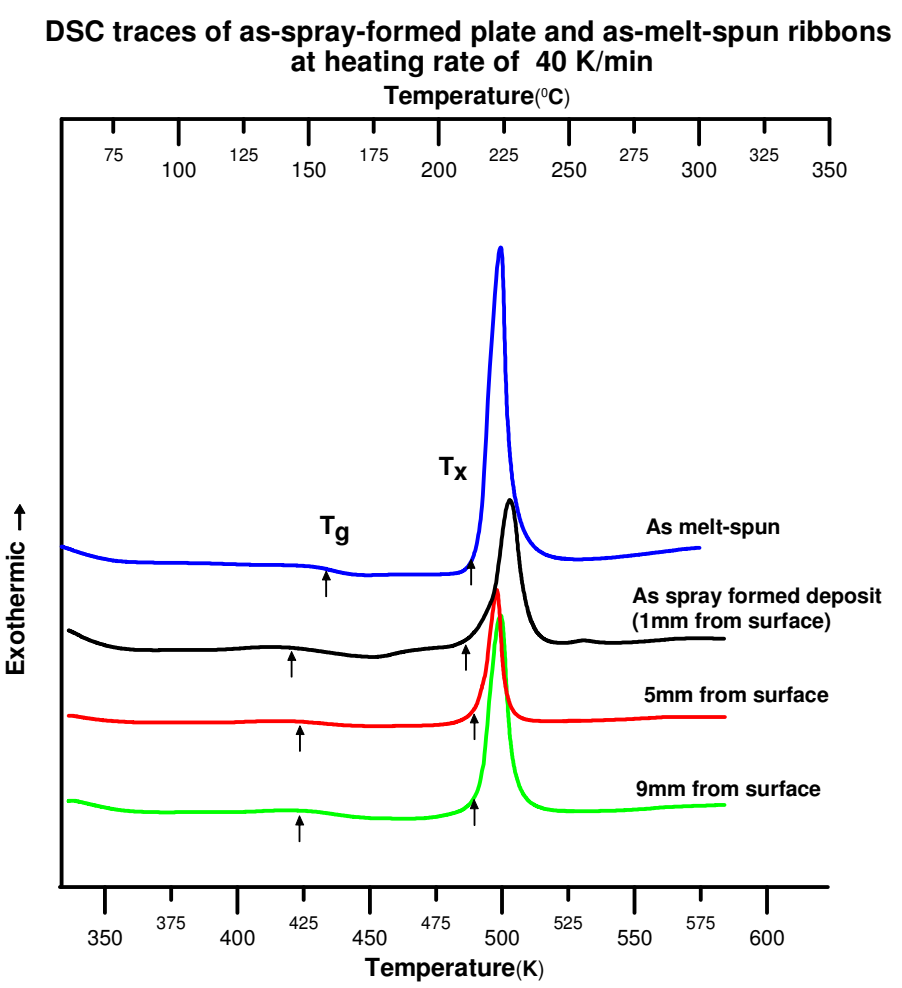

Fig. 4. DSC trace for as-spray-formed deposit and as-melt-spun ribbons at $40 \mathrm{~K} / \mathrm{min}$. 


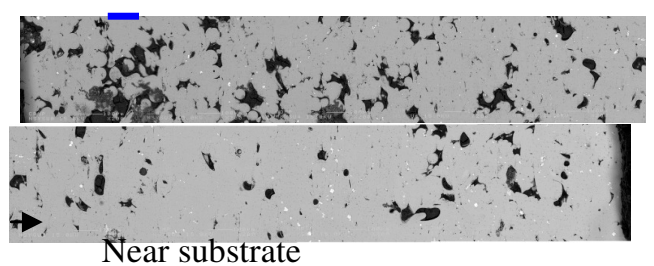

Fig. 5. The cross sectional micrograph of as-spray formed deposit (BEI image).

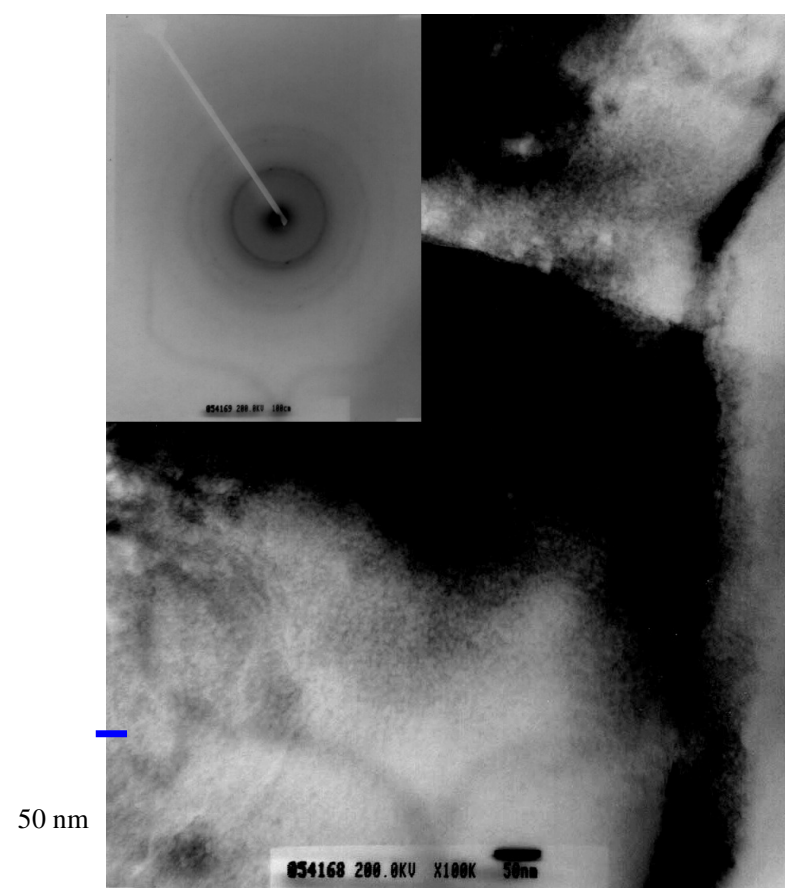

Fig. 6. TEM image and diffraction pattern of spray formed deposit (1 $\mathrm{mm}$ from free surface).

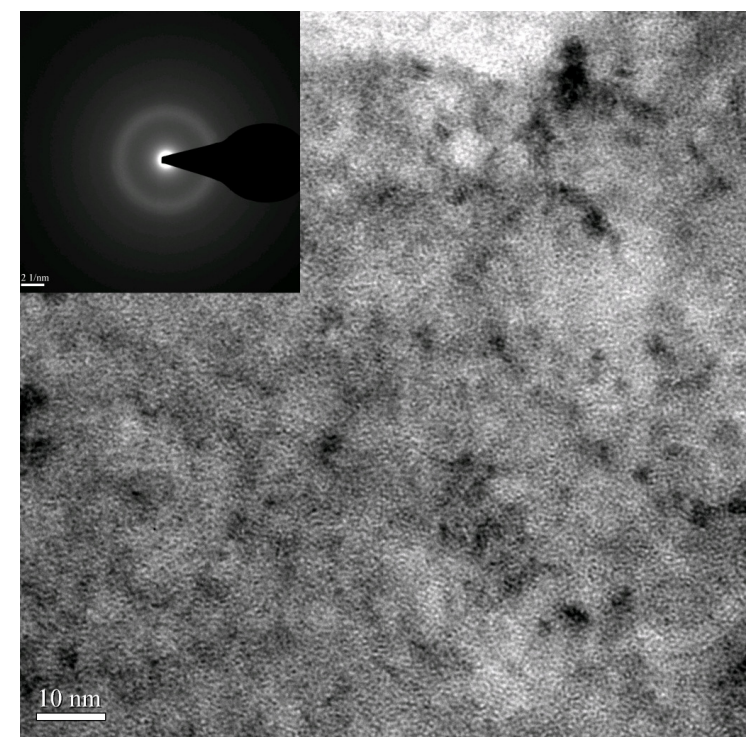

Fig. 7. TEM image and diffraction pattern of spray formed deposit (5 $\mathrm{mm}$ from free surface). 


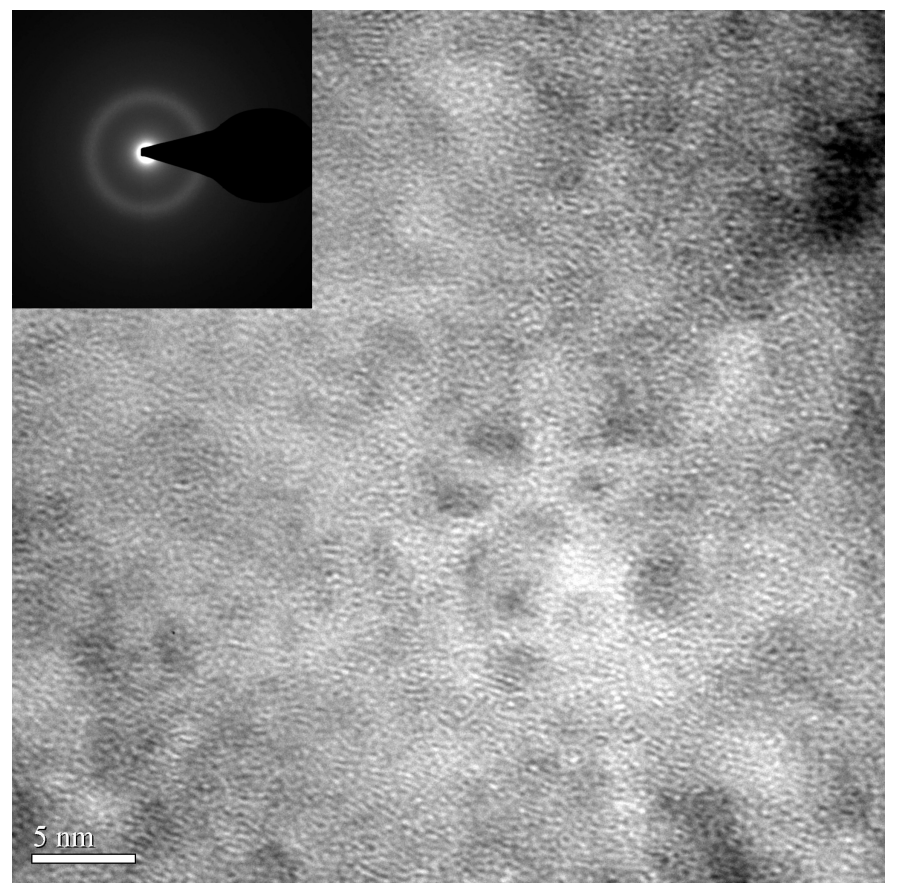

Fig. 8. TEM image and diffraction pattern of spray formed deposit $(9 \mathrm{~mm}$ from free surface).

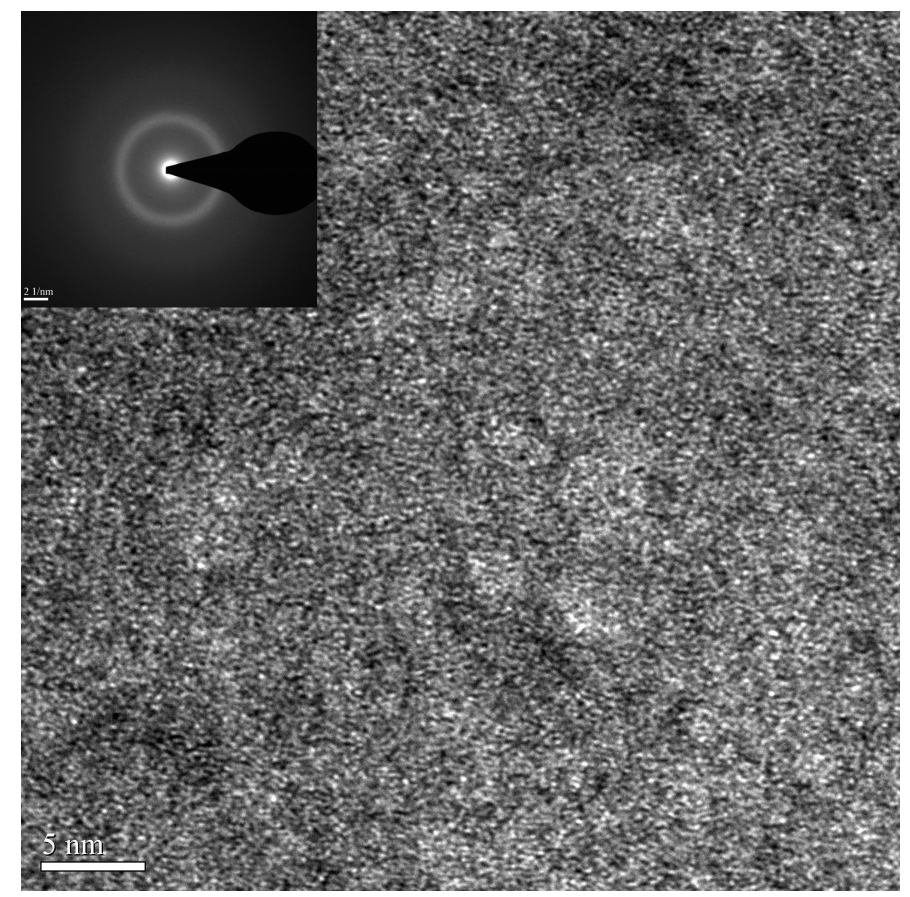

Fig. 9. TEM image and diffraction pattern of melt spun ribbons. 


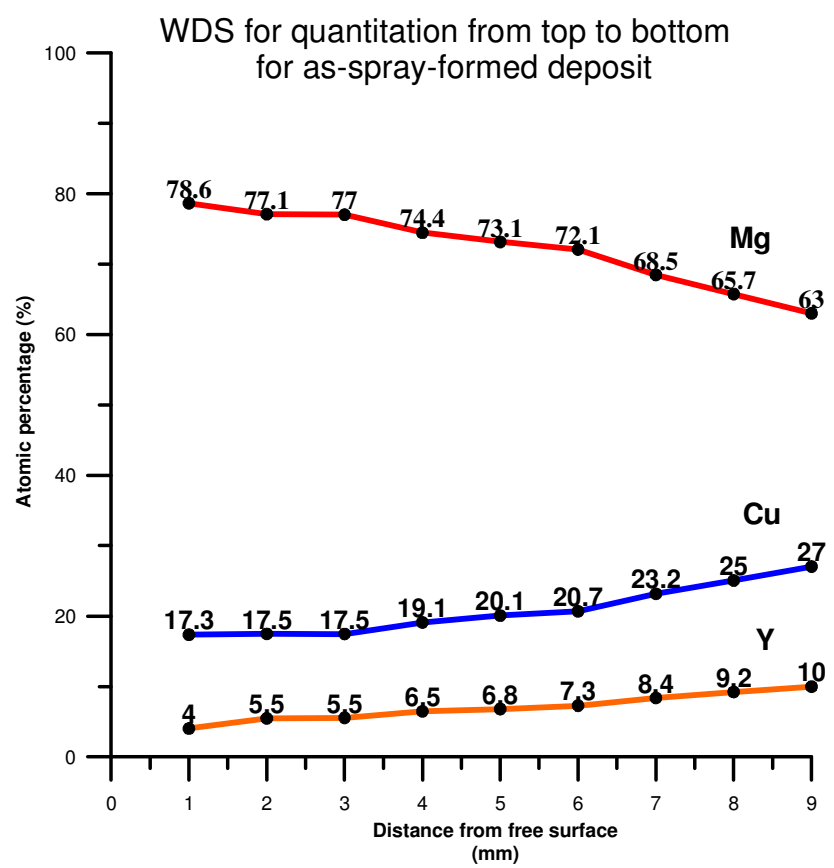

Fig. 10. Chemical composition for WDS of as- spray-formed deposit from top ( $1 \mathrm{~mm}$ from surface) to bottom ( $9 \mathrm{~mm}$ from surface).

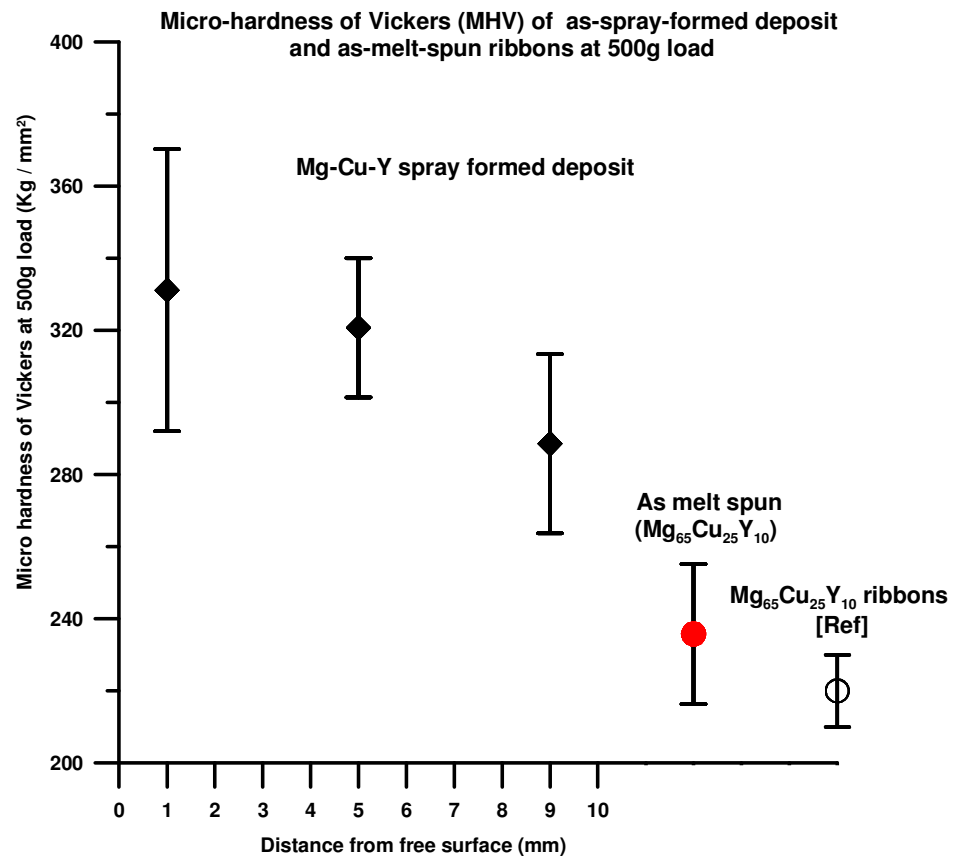

Fig. 11. The Micro-hardness of Vickers (MHV) of as-spray-formed deposit and asmelt-spun ribbons. 


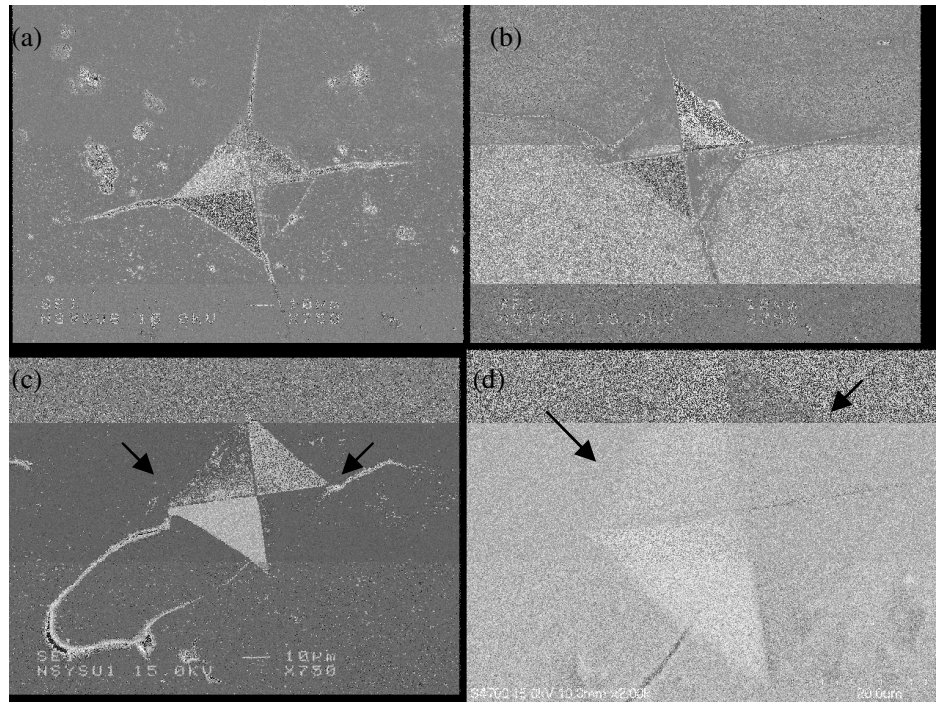

Fig.12. Micro-hardness of Vickers indentation of as-spray formed deposit (a) $1 \mathrm{~mm}$ from free surface (b) $5 \mathrm{~mm}$ from free surface (c) $9 \mathrm{~mm}$ from free surface (d) as-melt-spun ribbons.

TMA curves for as-spray-formed deposit and as-melt-spun ribbons (load $=50 \mathrm{mN}$; heating rate $=10 \mathrm{~K} / \mathrm{min}$ )

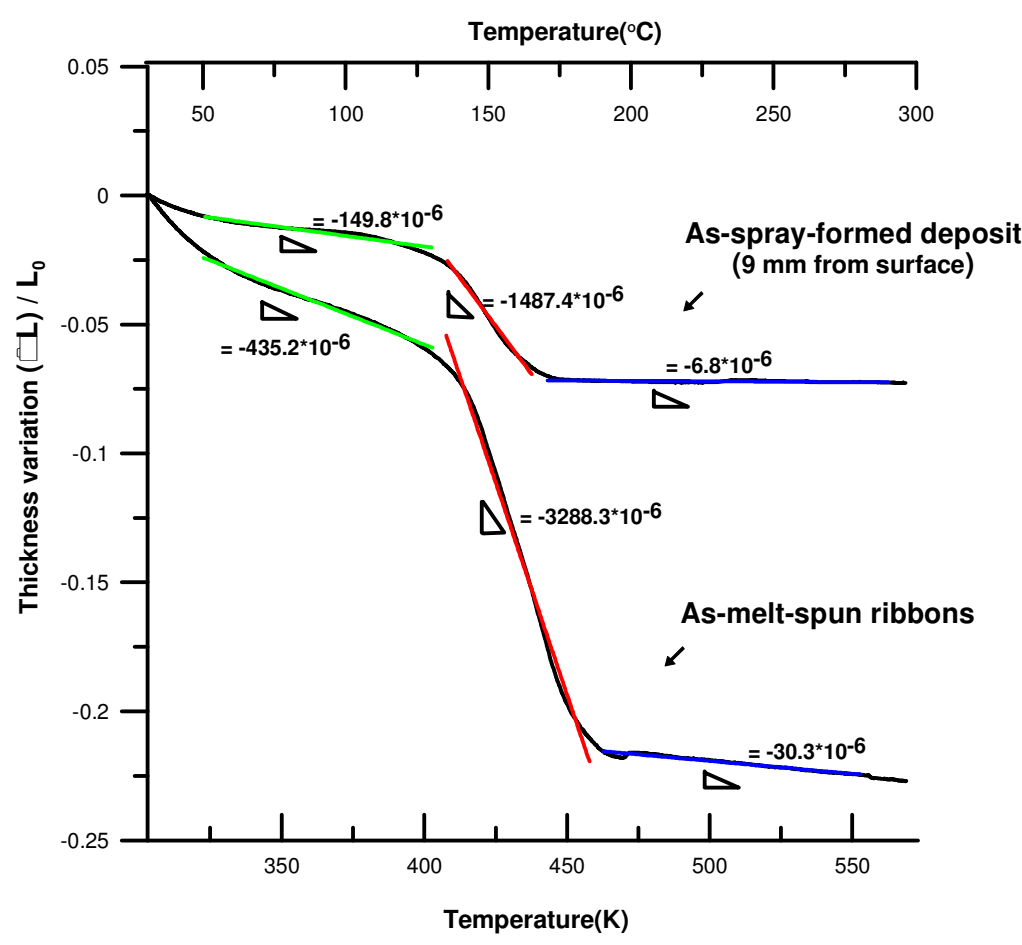

Fig. 13. TMA curves of as-spray-formed deposit and as-melt-spun ribbons. 